Revue

Revue de l'histoire des religions

de Ihistoire des religions

$1 \mid 2020$

Varia

\title{
Andrei TIMOTIN, La prière dans la tradition platonicienne, de Platon à Proclus
}

Turnhout, Brepols (« Recherches sur les rhétoriques religieuses », 22), 2017

Johann Goeken

\section{OpenEdition}

\section{Journals}

Édition électronique

URL : https://journals.openedition.org/rhr/10331

DOI : 10.4000/rhr.10331

ISSN : 2105-2573

Éditeur

Armand Colin

Édition imprimée

Date de publication : 1 mars 2020

Pagination : 134-136

ISBN : 978-2-200-93291-6

ISSN : 0035-1423

Référence électronique

Johann Goeken, «Andrei TıмотıN, La prière dans la tradition platonicienne, de Platon à Proclus », Revue de I'histoire des religions [En ligne], 1 | 2020, mis en ligne le 01 janvier 2021, consulté le 04 janvier 2023. URL : http://journals.openedition.org/rhr/10331 ; DOI : https://doi.org/10.4000/rhr.10331

Ce document a été généré automatiquement le 4 janvier 2023

Tous droits réservés 


\section{Andrei TIMOTIN, La prière dans la tradition platonicienne, de Platon à Proclus}

Turnhout, Brepols («Recherches sur les rhétoriques religieuses », 22), 2017

Johann Goeken

\section{RÉFÉRENCE}

Andrei Timotin, La prière dans la tradition platonicienne, de Platon à Proclus, Turnhout, Brepols (« Recherches sur les rhétoriques religieuses », 22), 2017, 23,5 cm, 294 p., $80 €$, ISBN 978-2-503-57482-0.

1 Issu d'un travail postdoctoral dirigé par Philippe Hoffmann, le livre d'Andrei Timotin sur la prière néoplatonicienne constitue une synthèse attendue, remarquable et passionnante. Composé d'une introduction, de sept chapitres et d'une conclusion, l'ouvrage étudie le devenir de la pensée platonicienne dans les analyses que les successeurs du fondateur de l'Académie ont consacrées à la prière. De manière diachronique et progressive, il présente d'abord les réflexions de Platon sur le sujet, puis les analyses contenues dans le Second Alcibiade pseudo-platonicien, avant de s'intéresser aux auteurs suivants: Maxime de Tyr, Plotin, Porphyre, Jamblique et Proclus. Dans ces chapitres, qui sont autant d'essais suggestifs, la position de chaque philosophe sur la question de la prière est analysée avec précision, de même que la façon dont chacun réagit en fonction de ses prédécesseurs, la référence platonicienne restant toujours de rigueur, quand d'autres auteurs (par exemple Plutarque, Apulée, Hermogène ou Julien) sont également mobilisés de façon ponctuelle dans la démonstration.

2 De manière générale, s'ils respectent la prière en tant que rite traditionnel de la vie religieuse, les philosophes ont l'ambition d'améliorer cette pratique, voire de la purifier 
de tout marchandage, de toute mesquinerie et de toute conception erronée de la nature divine. Pour ce faire, ils posent une série de questions récurrentes : comment le sage doit-il se comporter face au culte civique ? comment doit-il prier? doit-il prier selon l'usage de la cité ou autrement? À ces interrogations, les philosophes donnent des réponses qui varient en fonction du contexte historique et doctrinal. Outre l'aspect historique de la démarche, qui permet de suivre l'évolution d'une réflexion en se focalisant sur les jalons importants de la tradition platonicienne, le livre d'Andrei Timotin se recommande par l'intérêt qu'il accorde aux aspects rhétoriques des problèmes posés. La prière est en effet un acte de langage qui met en œuvre un processus complexe de persuasion et il faut alors se demander comment les dieux entendent les prières et s'ils les entendent. Dans cette perspective, plusieurs degrés ou types de prière sont individualisés et analysés par les penseurs, lesquels privilégient une prière comme exercice de méditation.

Dans le cas de Platon, l'ambiguïté qui consiste à respecter la religion traditionnelle tout en voulant épurer les gestes rituels s'exprime principalement dans la République et dans les Lois. Pour le philosophe, la divinité ne peut être fléchie ou influencée, les souhaits individuels formulés à l'adresse des dieux sont à bannir et la prière doit être un signe de vertu. Quant aux prières effectives qu'on trouve dans divers dialogues et qui sont souvent prononcées par Socrate lui-même, elles sont conçues comme des gages de sagesse et révèlent à quel point la recherche philosophique est profondément ancrée dans un contexte religieux, comme si le discours philosophique s'apparentait à un hymne. Par la suite le Second Alcibiade reflète comment la réflexion sur la prière était menée au sein de l'Académie après la mort de Platon et comment elle était devenue un thème important, en raison notamment de la mort de Socrate condamné pour impiété. Dans ce dialogue, l'examen met en garde contre les requêtes insensées ou non réfléchies qui peuvent s'avérer nuisibles, alors même qu'on pense demander un bien, et Socrate donne l'exemple qui consiste à demander, de façon prudente, « les biens », avec l'idée que les dieux savent ce qui est bien et qu'ils s'intéressent à l'âme de l'orant, plutôt qu'aux offrandes qu'il apporte. Plus de cinq siècles après le Second Alcibiade, Maxime de Tyr renouvelle la réflexion sur la prière, en particulier dans sa cinquième dialexis, qui est intitulée S'il faut prier. Réitérant la critique de la prière insensée tout en insistant sur la nécessité de savoir quel est le bien véritable avant de prier, le rhéteur médioplatonicien souligne que la prière est $a$ priori inutile et sans effet, dans la mesure où les affaires humaines dépendent soit de la providence, soit du destin, soit de la fortune, soit du travail humain. Dans ces conditions, il convient de redéfinir la prière pour la concevoir non comme une requête, mais comme une conversation avec la divinité et une démonstration de vertu. $\mathrm{Si}$, chez Platon, les prières acceptables concernent en fait des choses que l'orant désire avoir et restent donc des requêtes, Maxime considère qu'elles doivent concerner les biens présents, c'est-à-dire les biens spirituels qui dépendent de chacun.

Les analyses consacrées par A. Timotin à Plotin permettent de vérifier la sinuosité d'un raisonnement qui se complexifie en fonction d'interrogations toujours renouvelées. $\mathrm{Si}$ l'on retrouve chez Plotin le thème de l'inutilité de prier pour des choses qui ne dépendent que de nous, la réflexion s'enrichit de développements inédits, par exemple sur la contrainte des astres (que Plotin réfute en s'opposant ainsi aux gnostiques), sur les rapports avec la magie ou la sorcellerie et sur la prière pensée indépendamment du langage et conçue comme contemplation intellectuelle, la communication noétique (c'est-à-dire non articulée) restant l'apanage des seuls philosophes. Dans la lignée de 
Plotin, Porphyre prend la défense de la prière tout en rappelant que sa nécessité provient de son universalité et qu'il est inconcevable de prétendre persuader les dieux (dont la nature est intellective et donc impartiale) en priant ou de jouer sur les affects avec eux. Plus précisément Porphyre distingue plusieurs types ou niveaux d'offrandes et d'adresses en fonction des dieux concernés. Au dieu suprême conviennent le sacrifice intellectuel et la contemplation silencieuse, aux dieux intelligibles l'hymne et la parole chantée, aux dieux civiques le sacrifice matériel d'offrandes végétales et le respect des traditions ancestrales, aux démons mauvais les sacrifices sanglants et les supplications. Bien que le sacrifice silencieux se situe au sommet de la hiérarchie pour Porphyre, divers degrés de communication avec le divin sont envisagés pour se conformer à la dignité des interlocuteurs et aux réalités de la croyance. Dans ces conditions, seul le sage sait prier et il peut le faire non pas au moyen du langage mais par ses œuvres, tout en continuant (et c'est là une différence par rapport à Plotin) à pouvoir demander les biens spirituels. Mais si Plotin et Porphyre dévalorisent les cultes traditionnels pour promouvoir une religion intérieure, Jamblique réhabilite le rituel, dans un contexte où le néoplatonisme se définit comme religion scientifique par opposition au christianisme jugé irrationnel. La prière, qui est fondée sur des textes sacrés, s'accomplit en plusieurs étapes impliquant une remontée jusqu'à l'union avec la divinité et un impact sur celui qui prie. Avec Proclus, enfin, le silence et l'isolement sont privilégiés dans le culte divin et la religion obéit à un processus de textualisation, la recherche philosophique et le commentaire théologique s'apparentant à une démarche hymnographique.

5 Au total, en s'intéressant au problème précis de la prière, Andrei Timotin montre avec efficacité comment la tradition platonicienne se caractérise dans l'ensemble par une attitude ambivalente, laquelle consiste à critiquer la tradition rituelle tout en tâchant d'édifier une religion philosophique. Les textes sont analysés avec finesse et le propos se distingue par sa clarté. Quant à l'attention prêtée au problème de la persuasion, elle s'avère féconde en ce sens qu'elle permet de dégager une dialectique du silence et de la parole, une réflexion sur les sentiments et l'affectivité de l'orant, et donc une relation forte entre philosophie, religion et rhétorique.

\section{AUTEURS}

JOHANN GOEKEN

Université de Strasbourg. 